\title{
93. Notes on Comparative Chromosome Analyses in Human Cell Lines in Tissue Culture
}

\author{
A Preliminary Note*) \\ By Akio Awa,**) Sajiro Makino, ${ }^{* *}$ \\ and Nariaki Mıчамото ${ }^{* * *}$ \\ (Comm. by Yoshimaro TANAKA, M.J.A., June 12, 1964)
}

Current literature has shown that long-term maintenance of human as well as of mammalian cell cultures is frequently associated with heteroploid transformations, and that there is a general similarity between malignant cells in situ and cells maintained in vitro with respect to their uncontrollable growth capacity and some other properties. A comparative study at the chromosomal level between neoplastic cells in situ and established cell lines in vitro is of significance. The present study deals with a comparative chromosomal analysis in human primary cells and two cell lines, HL-C and HeLa, in culture.

Materials and Methods. The HL-C line of human fetal lung origin and the HeLa line (human cervical carcinoma), both maintained in vitro, were selected for this study.

Chromosome preparations were made from cells on the 3rd day after subcultivation, or the next day after the change of fresh nutrient medium, mostly by means of air-drying technique (Moorhead et al. 1960). The cells were also stained and squashed with acetic orcein. As control, leucocyte chromosome samples were prepared from peripheral blood cultures of normal male and female individuals: cells were fixed on the $3 \mathrm{rd}$ or 4 th day of cultivation, and chromosome preparations were made as described above. The chromosomes from enlarged photographs were analyzed according to the Denver standard system of normal human chromosomes.

Chromosome Numbers. Control group: A total of 200 metaphase cells, derived from healthy normal male and female individuals, were examined: they had a normal number of 46 in high frequency.

HL-C cells: Chromosome preparations were made in June and July, 1963, i.e., approximately 5 years after establishing as a stable

*) Contribution No. 633 from the Zoological Institute, Faculty of Science, Hokkaido University, Sapporo.

**) Zoological Institute, Hokkaido University, Sapporo.

***) Department of Internal Medicine, Kyushu University School of Medicine, Fukuoka.

The authors are greatly indebted to Drs. M. S. Sasaki, Y. Kimura, T. Sofuni, and

K. Yamada for their valuable technical assistance. 
cell line (Nakanishi et al. 1959). In the present study, the modal chromosome number of this line was found to be 63 with a frequency of 32 per cent (Table I). The first sample (June) showed that cells other than 63 chromosomes were fairly frequent, with a narrow numerical variation around the modal value. In the second sample (July), modal cells occurred in higher frequency than the former. Polyploid cells were low in occurrence in both specimens.

Table I. Chromosome-number distribution of HL-C and HeLa cells

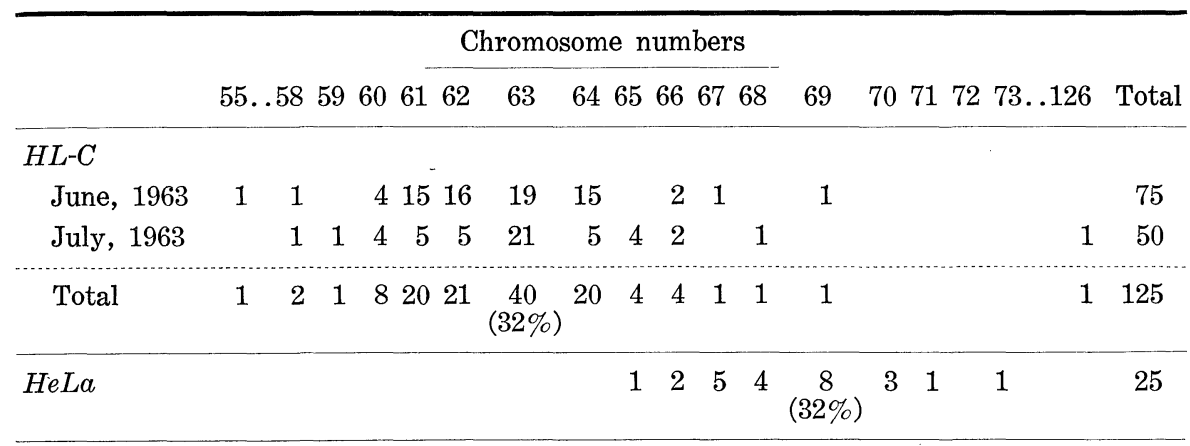

HeLa cells: Recent observations revealed that the modal chromosome number of this cell line was 69 being 32 per cent in frequency, with variation limits lying between 65 and 73 (Table I).

Chromosome Morphology. Cultured leucocytes from normal subjects showed 46 chromosomes in both sexes with a standard karyotype of Denver system in all cells studied.

The chromosomes of modal cells from both HL-C and HeLa lines could be arranged and classified into seven groups in reference to their size and shape (Figs. 1-2). In the two cell lines, the number of chromosomes in each group increased nearly proportionally from each corresponding group of a normal complement, although the number of small elements such as in groups 19-20 and 21-22 was in most cases fewer than the expected. Cells of both lines contained constantly some chromosomes in groups 13-15 and 21-22, which had a satellite on top of each short arm. Association of satellited chromosomes was frequent, as generally occurred in the normal human metaphases. The present findings thus imply that the karyotypes of HL-C and HeLa cells seem to be analogous to the standard human karyotype, though there is a considerable difference of modal chromosome numbers between those cell lines.

In addition to the above features, there were present unusual chromosomes specific to each karyotype. For instance, a minute chromosome occurred in the HL-C complement, nominated as " $\mathrm{m}$ " in Figure 1: it carried a centromere-like structure. 


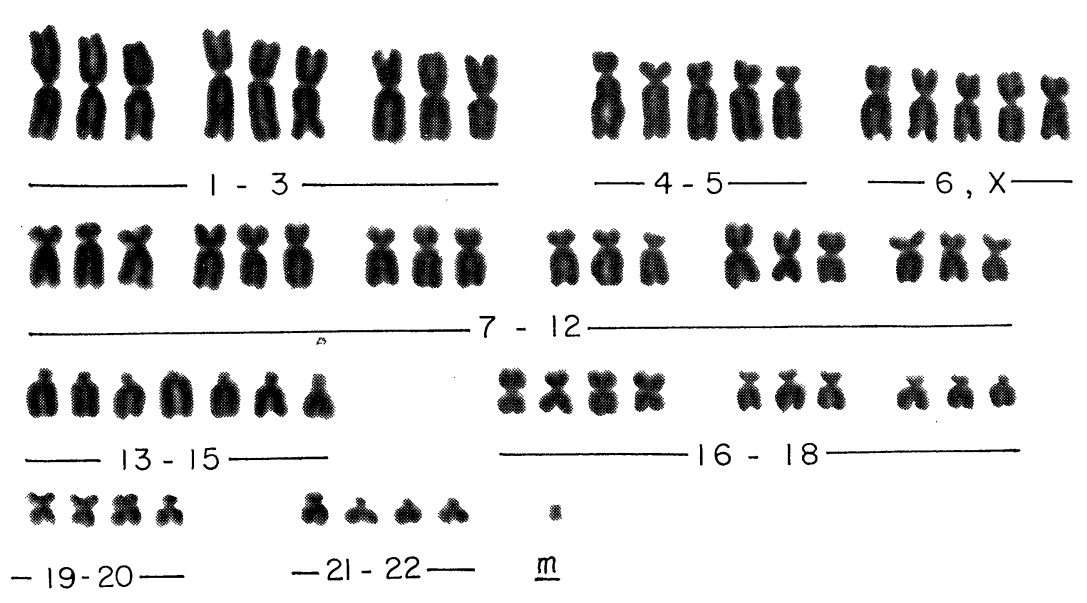

\section{$-19-20+1-21-22-1-m$}
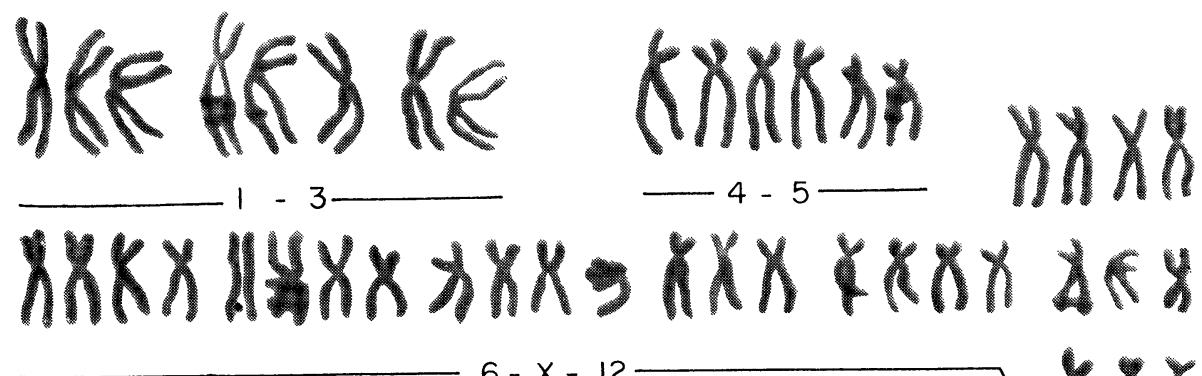

AXAKIOAOA

$-13-15$
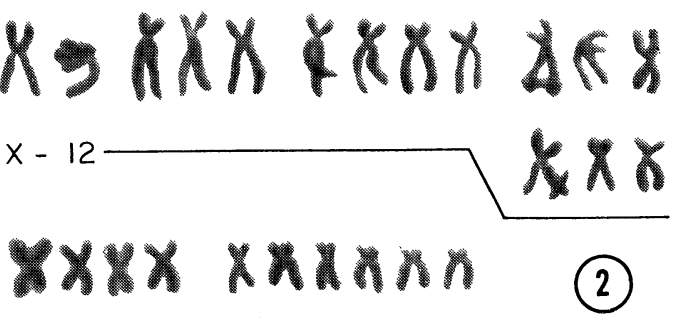

$6 ; x-12$

$x \times x$

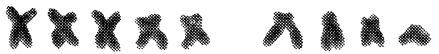 \\ $-19-20--21-22-Y-$}

$16-18$

Figs. 1 and 2. Karyotypes of HL-C and HeLa cells in vitro.

Fig. 1. An HL-C cell, 63 chromosomes. $m$ : a minute chromosome.

Fig. 2. A HeLa cell, 71 chromosomes.

Remarks. Current advances in tissue culture techniques have facilitated reliable and precise studies of human and mammalian chromosomes. It has generally been accepted that long term maintenance of mammalian cell cultures is frequently associated with heteroploid transformations (cf. Hsu 1961). The relation between chromosomal changes in established cell lines and neoplastic changes of cells is of special interest.

In the light of the present results, the following two problems will be discussed:-

In the course of maintenance of cell lines in vitro, the modal chromosome number generally tends to decrease towards lower limits even in heteroploid cell lines. In earlier reports so far appeared, the 
chromosome numbers of HeLa and its derivatives fell in the hypotetraploid range with a mode at the lower 80 s or higher $70 \mathrm{~s}$. In this study the modal chromosome number of the HeLa line was found to lie between 65 and 73 with the highest frequency at 69 . The modal chromosome number of HL-C line was first reported to be 77 by Nakanishi et al. (1959). Later on, Awa et al. (1961) found the modal number as 68, while Mizutani (1962) and the present study reported as 63 or thereabout. Such a numerical decrease in the number of chromosomes during serial passages may possibly be attributable to non-disjunction of certain chromosomes. The analysis of chromosomes in both lines in reference to Denver system revealed that the number of chromosomes in each group increased nearly proportionally from the corresponding groups of the normal human karyotype, due possibly to random loss of chromosomes in the complement of modal cells during serial passages.

Further, there was a cytological feature to indicate that the karyotypes of HL-C and HeLa cell lines were analogous to some extent to the standard human karyotype, though the chromosome numbers and constitutions differed from each other. Particularly, satellited chromosomes and satellite association have remained to occur in established cell lines in vitro, though gross structural and numerical changes of chromosomes had occurred in those lines. A similar situation has been found to occur in human normal and neoplastic cell lines cultivated for a long period of time (Auersperg 1964, Auersperg and Hawryluk 1962, Clausen and Syverton 1962, de Carli et al. 1963, Norryd and Fjelde 1963, and others, cf. Hsu 1961). Furthermore, a karyotypic similarity has been reported in the majority of human cell lines in vitro, regardless of the origin of tissues. However, a karyotypic analogy found in cell lines in vitro does not always reflect genetic uniformity among them.

Current karyological studies have revealed that there exists in a variety of human tumors a certain karyotypic pattern similar to that of normal human karyotype with or without the occurrence of several marker elements (Ishihara et al. 1961, 1963, 1963, Makino et al. 1964). A similarity in general properties between malignant cells in situ and established cell lines in vitro might be attributed in part to a karyotypic analogy between those two types of cells. Further work on this problem is in progress.

In conclusion, the chromosome analysis was undertaken in HL-C and HeLa cell lines in vitro, in comparison with those of human cultured leucocytes. There was a general tendency to indicate that the karyotypes of both cell lines were analogous to the normal human karyotype, regardless of the number and constitution of chromosomes. 


\section{References}

Auersperg, N. (1964): J. Nat. Cancer Inst., 32, 135.

Auersperg, N., and A. P. Hawryluk (1962): J. Nat. Cancer Inst., 28, 605.

Awa, A., Y. Ohnuki, and C. M. Pomerat (1961): Texas Rep. Biol. Med., 19, 518.

Chu, E. H. Y., and N. H. Giles (1958): J. Nat. Cancer Inst., 20, 383.

Clausen, J. J., and J. T. Syverton (1962): J. Nat. Cancer Inst., 28, 117.

de Carli, L., J. J. Maio, and F. Nuzzo (1963): Nat. Cancer Inst., 31, 1501.

Defendi, V., R. B. Billingham, W. K. Silvers, and P. S. Moorhead (1960): J. Nat. Cancer Inst., 25, 359.

Hsu, T. C. (1954): Texas Rep. Biol. Med., 12, 833.

(1961): Internat. Rev. Cytol., 12, 69.

Ishihara, T., Y. Kikuchi, and A. A. Sandberg (1963): J. Nat. Cancer Inst., 30, 1303. Ishihara, T., G. E. Moore, and A. A. Sandberg (1961): J. Nat. Cancer Inst., 27, 893. Ishihara, T., ane A. A. Sandberg (1963): Cancer, 16, 885.

Levan, A. (1959): In Genetics and Cancer. University of Texas Press, Austin, p. 151. Makino, S., M. S. Sasaki, and A. Tonomura: J. Nat. Cancer Inst., 32, 741.

Mizutani, M. (1962): J. Fac. Sci., Hokkaido Univ. Ser. VI, Zool., 15, 18.

Moorhead, P. S., P. C. Nowell, W. J. Mellman, D. M. Battips, and D. A. Hungerford (1960): Exp. Cell Research, 20, 613.

Nakanishi, Y. H., M. Mizutani, and C. M. Pomerat (1959): Texas Rep. Biol. Med., 17, 542.

Norryd, C., and A. Fjelde (1963): Cancer Research, 23, 197.

For detailed information, refer to Hsu, T. C. (1961). 